\title{
piRNAs warrant investigation in Rett Syndrome: An omics perspective
}

\author{
Alka Saxena*, Dave Tang and Piero Carninci \\ RIKEN Omics Science Center, Yokohama, Japan
}

\begin{abstract}
Mutations in the $M E C P 2$ gene are found in a large proportion of girls with Rett Syndrome. Despite extensive research, the principal role of $\mathrm{MeCP} 2$ protein remains elusive. Is MeCP2 a regulator of genes, acting in concert with co-activators and co-repressors, predominantly as an activator of target genes or is it a methyl CpG binding protein acting globally to change the chromatin state and to supress transcription from repeat elements? If MeCP2 has no specific targets in the genome, what causes the differential expression of specific genes in the Mecp 2 knockout mouse brain? We discuss the discrepancies in current data and propose a hypothesis to reconcile some differences in the two viewpoints. Since transcripts from repeat elements contribute to piRNA biogenesis, we propose that piRNA levels may be higher in the absence of MeCP2 and that increased piRNA levels may contribute to the mis-regulation of some genes seen in the Mecp 2 knockout mouse brain. We provide preliminary data showing an increase in piRNAs in the Mecp2 knockout mouse cerebellum. Our investigation suggests that global piRNA levels may be elevated in the Mecp2 knockout mouse cerebellum and strongly supports further investigation of piRNAs in Rett syndrome.
\end{abstract}

Keywords: Rett Syndrome, MeCP2, piRNAs, LINE 1, short RNAs

Rett Syndrome (RTT), a severe neurodevelopmental disorder, leads to intellectual disability in girls. After a normal prenatal and postnatal period, patients usually present with developmental delay between 6 and 18 months of age, followed by the development of stereotypic hand movements and loss of acquired skills including voluntary hand use, language and communication. This regression is characteristic of Rett Syndrome which, in $97 \%$ of clinically diagnosed classic cases and $70 \%$ of atypical cases, is caused by mutations in the methyl $\mathrm{CpG}$ binding protein 2 gene, $(M E C P 2)$ [1]. In some patients with atypical Rett Syndrome, where some but not all clinical features are seen, mutations in CDKL5 [2] or FOXG1 [3] are found, albeit infrequently. Diagnosis of Rett Syndrome is based on clinical criteria [4] and confirmed upon detection of a mutation in MECP2, CDKL5 or FOXG1. However, in approximately $20 \%$ of girls clinically diagnosed with classic or atypical Rett syndrome, mutations cannot be detected in either of these genes.

$M E C P 2$ gene undergoes $\mathrm{X}$ chromosome inactivation (XCI) [5], which means that in any cell with two

*Corresponding author: Alka Saxena, RIKEN Omics Science Center, Yokohama, Japan. E-mail: alka@gsc.riken.jp.
$\mathrm{X}$ chromosomes, RNA transcripts arise only from the $M E C P 2$ gene on the active $\mathrm{X}$ chromosome. This is because the MECP2 gene on the inactive $\mathrm{X}$ chromosome has been silenced. Chaumeil et al. demonstrated, through in-situ hybridization in mouse ES cells, that the Mecp 2 gene moves inside the silencing compartment of Xist on the 4th day after differentiation [6]. Although some genes are known to escape $\mathrm{X}$ inactivation in humans and mouse [7-10], Carrel et al. showed using rodent/human somatic hybrid cell lines that in humans MECP2 transcripts are not expressed from the inactive $\mathrm{X}$ chromosome [7]. Due to the random nature of $\mathrm{X}$ inactivation, part of the clinical variability in RTT is attributed to the differences in the $\mathrm{X}$ inactivation status of patients [11-13], however more recent data suggest $\mathrm{X}$ inactivation status may not adequately explain the phenotypic variations [14].

$M E C P 2$ gene is composed of 4 exons and generates two transcripts which encode two nearly identical protein isoforms [15,16]. MeCP2_e1, which commences translation from exon 1 , is encoded from a transcript encompassing exons 1, 3 and 4; and MeCP2_e2, which starts translation from the end of exon 2, is generated from a transcript arising from exons 1, 2, 3 and 4, where exon 1 and most of exon 2 form the 5'UTR [15, 
16]. Although $M E C P 2$ is expressed in all tissues, semiquantitative PCR analysis has shown that Mecp2_el may have a higher expression level over Mecp2_e2 in the brain [16]. Mutations in exons 3 and 4 affect both protein isoforms and are frequently found in Rett patients. Mutations in exon 1 can cause Rett syndrome despite the fact that mutations in exon 1 do not affect the coding region of the MeCP2_e2 protein. Interestingly, mutations in exon 2 of the gene, which have the potential to affect the MeCP2_e2 isoform alone, have so far not been found in patients. While earlier work on an Australian patient with a recurrent deletion in exon 1 of $M E C P 2$ gene demonstrated the absence of $\mathrm{MeCP} 2 \mathrm{e} 2$ protein correlated with $\mathrm{X}$ inactivation status, suggesting translational interference from the mutation [17], a recent publication found no evidence of loss of MeCP2_e2 protein in a Canadian patient with a similar mutation indicating that some patients may present with clinical features of Rett syndrome even in the presence of a fully functional MeCP2_e2 isoform [18]. Interestingly, this data also suggests that despite high sequence similarities there is no functional redundancy between the two protein isoforms.

Due to its property to bind methylated DNA with high affinity and its association with repressor complexes consisting of HDAC $1 / 2$ and $\operatorname{Sin} 3 \mathrm{~A}, \mathrm{MeCP} 2$ was believed to function as a transcriptional repressor [19, 20]. The MeCP2-DNA interaction was shown to result in chromatin compaction, which is also correlated with silencing of chromatin [21]. Subsequent studies revealed that $\mathrm{MeCP} 2$ had binding affinity to methylated DNA as well as non-methylated DNA [22]. Absence of $\mathrm{MeCP} 2$ in mouse brains also results in an increase in H3Ac levels, suggesting a role for MeCP2 in chromatin modification [23,24]. Recent data suggest that MeCP2 protein may be a regulator of transcription, acting in concert with activators as well as repressors to regulate gene expression. Yasui et al. first reported that promoter occupancy by MeCP2 may not result in gene silencing [25]. Using a custom tiling array of selected chromosomal regions totalling 26.3 $\mathrm{Mb}$, they performed ChIP-chip analysis on SH-SY5Y cells with antibodies against MeCP2 and RNA polymerase II. The data revealed co-occupancy of MeCP2 and RNA Polymerase II at selected promoters suggesting that MeCP2 binding may not be correlated to gene repression [25]. Using ChIP-chip assays for 24,275 promoters, they demonstrated that only 2600-4300 promoters were occupied by MeCP2, of which 1534 promoters showed strongest enrichment. Comparison with gene expression arrays in the same cell lines revealed that almost $63 \%$ of the "strongest" promoters were expressed in SH-SY5Y cells. Subsequent MeDIP-ChIP analysis revealed that just $2.2 \%$ of methylated promoters were occupied by MeCP2 [25]. These data were supported in part by Chahrour et al. who used microarrays to determine differentially expressed genes in the hypothalamus of 6 week old Mecp 2 knockout (KO) mouse and in the hypothalamus of a mouse model that overexpressed Mecp 2 under its endogenous promoter (Tg) [26]. Combining their data from the $\mathrm{KO}$ and $\mathrm{Tg}$ models, they identified 2561 genes as direct targets of $\mathrm{MeCP} 2$, of which $\sim 85 \%$ were activated by $\mathrm{MeCP} 2$ and $\sim 15 \%$ were repressed by MeCP2 [26]. Using mass spectrometry on proteins co-immunoprecipitated with an anti-MeCP2 antibody, they identified CREB1 as a co-activator associated with $\mathrm{MeCP} 2$ and demonstrated co-occupancy of the two proteins at an activated target Sst [26]. Together, these data established MeCP2 as an activator of transcription $[25,26]$. Thus transcriptional mis-regulation is believed to underlie the phenotype seen in patients with mutations in the $M E C P 2$ gene. In view of the fact that FOXG1 is a member of the forkhead family of transcription regulators, it is likely that in patients carrying mutations in FOXG1, mis-regulation of genes may contribute to the phenotypic features. The molecular pathology leading to the clinical phenotype of Rett Syndrome in mutation negative patients remains unknown. While much has been reported on the misregulation of specific genes after MeCP2 knockdown (KD) or KO, such studies have not yet been reported for FOXG1. Other studies reveal subtle changes in the expression levels of specific genes after MeCP2 KD or in the Mecp $2 \mathrm{KO}$ mouse brain rather than genome wide transcriptional mis-regulation [27-29].

However, a recent report suggests that the absence of a functional MeCP2 may result widespread misregulation of repeat elements. Skene et al. investigated $\mathrm{MeCP} 2$ binding on selected loci in the mature mouse brain using ChIP-qPCR and demonstrated that MeCP2 was enriched all across the loci, but the enrichment was reduced over $\mathrm{CpG}$ islands, which are generally methylation free [24]. With bisulfite modification and sequencing of selected loci they demonstrated the recovery of predominantly methylated chromatin from the MeCP2 ChIP, re-emphasizing the role of MeCP2 as a methyl $\mathrm{CpG}$ binding protein [24]. Based on their investigation of the histone acetylation status by Western blotting and H3Ac ChIP-qPCR at 100 loci, they concluded that the association of MeCP2 with chromatin causes a genome-wide decrease in histone acetylation [24]. To investigate the binding sites of MeCP2 
genome wide, Skene et al. performed MeCP2-ChIPsequencing on the whole brain. Despite deep sequencing, they did not find peaks of MeCP2 occupancy, but found reads which coincided with methylated regions of the genome. Since they did not uncover specific binding targets of $\mathrm{MeCP} 2$ in the genome, they hypothesized that MeCP2 may act at a global level, most likely to supress transcription from the repeat regions of the genome [24]. Using qPCR, they demonstrated a 1.6 fold increase in transcripts arising from repeat sequences such as LINE-1, intra-cisternal A particles (IAPs) and major satellite DNA in the nuclear fraction of the Mecp $2 \mathrm{KO}$ mouse brain. Based on their data they proposed that $\mathrm{MeCP} 2$ functions to repress spurious transcription of repeat elements [24] rather than to activate specific gene targets. An earlier investigation into the association between MeCP2 and LINE- 1 and Alus had revealed that MeCP2 repressed LINE-1 expression and transposition, but activated Alu expression [30]. The role of MeCP2 in repressing transcription and transposition of LINE-1 elements was also corroborated by independent studies from the Gage Lab that showed that LINE-1 is over expressed in neuron progenitor cells after KD of MeCP2 and in neurons derived from Rett patients [31]. The data from Yasui et al. suggests that MeCP2 displays limited binding to methylated sites [25] and from Chahrour et al. proposes that $\mathrm{MeCP} 2$ acts as a transcriptional activator of specific targets [26]. In contrast, the data from Skene et al. suggests that MeCP2 binds methylated DNA, is a modulator of global chromatin state and may not have specific gene targets [24]. We note that some of these studies were conducted using microarrays or custom tiling arrays, which are generally limited to gene specific probes and exclude repeat sequences. Despite contradictory inferences on $\mathrm{MeCP} 2$ function, the fact remains that specific genes are mis-expressed and repeat elements are over-expressed in Mecp $2 \mathrm{KO}$ mice. To reconcile the two opposing views, an alternative model would suggest that the key role of MeCP2 is to silence LINEs and similar repeat elements globally and that the observed mis-expression of genes is a downstream consequence of mis-expressed repeat elements.

Several recent reports suggest that non-coding RNAs play a role in the regulation of transcription through epigenetic modifications, [for a review see [32]]. Repeat elements, particularly LINEs, are known to participate in the silencing of genes on the X chromosome [33]. Expression of LINEs in the vicinity of genes is instrumental for their inclusion into the Xist silencing compartment [33]. It is not yet known whether transcripts from LINE elements are associated with chromatin remodelling complexes to mediate epigenetic changes and fine-tune gene transcription, but we note that the elevated repeat elements were found in the nuclear compartment of the Mecp2 KO mouse brain cells [24] and there is emerging evidence of enrichment of LINEs in nuclear and chromatin fraction of cells [34]. A recent report using a retrotransposon capture sequencing technique (RC-seq) reveals that somatic transposition of LINE-1 (L1) in the hippocampus results in insertions, predominantly in exons and introns of protein coding genes [35]. Comparing microarray data with their RCseq data, Baillie et al. reported that intronic L1 insertions are likely to cause overexpression of such genes in the brain, suggesting a regulatory role for L1 [35]. It is not clear if the increase in retrotransposon expression in the Mecp $2 \mathrm{KO}$ brain leads to their active transposition even in post mitotic neurons. Random integration of transposons is suppressed in differentiated somatic cells by transcriptional [36] and post-transcriptional mechanisms [37]. It would be interesting to investigate if somatic retrotransposition is increased in the Mecp 2 $\mathrm{KO}$ brain and whether overexpressed genes identified in Mecp $2 \mathrm{KO}$ mouse show novel intronic L1 insertion events.

Retrotransposons such as LINEs can be further processed into short 21-24 nucleotide double stranded siRNAs [38] or into single stranded 24-31 nucleotide long piRNAs $[39,40]$. Watanabe et al. described in mouse oocytes dicer dependent double stranded endogenous siRNAs mapping exclusively to retrotransposons or expressed mRNA transcripts [38]. While the presence of endogenous siRNAs has not been demonstrated in the mouse brain, given that such short RNAs are shown to regulate the expression levels of specific genes and specific retrotransposons $[38,41]$, and that dysfunctional MeCP2 may result in the overexpression of LINE1 [24,31], it would be interesting to investigate the presence of endogenous siRNAs in the MeCP2 KO mouse brain.

piRNAs are germ line specific short RNAs of size 24 to 31 nucleotides generated through dicer independent processing of long single strand RNA transcripts. piRNAs interact with the PIWI proteins (MILI, MIWI and MIWI2 in mouse) [39,40] and their function, though not fully understood, appears to relate to silencing of transposons especially LINE-1 [39,40,42] intracisternal A particles $[39,40]$ and specific genes through DNA hypermethylation [43]. In mouse testis, $17 \%$ of piRNAs bound to the MIWI protein map to repeats including LINEs, SINEs and LTRs [40]. In addition, through 
a unique ping-pong cycle, piRNAs are amplified from existing retrotransposon transcripts, mostly LINE-1 elements $[44,45]$. This amplification cycle also results in the depletion of LINE-1 in germ line cells and is believed to deplete the levels of retrotransposon transcripts after differentiation [42]. Thus piRNAs regulate expression of LINEs and Intracisternal A particles both transcriptionally and post transcriptionally. Interestingly, piRNAs have recently been shown to regulate expression of a single imprinted gene in an imprinted locus in mouse spermatogonia via DNA methylation by piRNA targeting of a non coding RNA (pitRNA) arising from the locus [43]. It is as yet not known if such specific targeting by piRNAs is a widespread phenomenon, nevertheless it highlights a mechanism through which piRNAs may regulate expression of specific genes.

Until recently, piRNAs and their associated proteins were presumed to be germ line specific in mouse, but a report published last year confirmed the presence of MIWI and its associated piRNAs in the mouse hippocampus through sequencing, RIP-qPCR, northern blots, western blots and in situ hybridization studies [46]. Through bioinformatics analysis, Lee at al. identified specific piRNAs expressed in the brain and showed through piRNA inhibition studies, that one piRNA in the brain, DQ541777, may play a role in regulating the size of dendritic spines [46]. It appears plausible that in the absence of MeCP2, over expression of repeat elements, particularly LINE-1 may result in an increase in piRNA amplification from transposons. It would be interesting to investigate whether akin to germ line cells, in brain also, the increase in piRNAs result in depletion of retrotransposon transcript levels through transcriptional and post transcriptional silencing. The mechanism of transcriptional silencing by piRNAs through DNA methylation may require recruitment of repressor complexes by proteins that bind methylated DNA, including MeCP2, thus highlighting a feedback loop for $\mathrm{MeCP} 2$ requirement.

To investigate our hypothesis that piRNAs may be overexpressed in the Mecp $2 \mathrm{KO}$ mouse brain, we analysed a short RNA library made from mouse cerebellum [47]. To identify miRNAs differentially expressed in the cerebellum, Wu et al. performed short RNA sequencing of pooled 6 week old pre-symptomatic wildtype and Mecp2 KO cerebellum ( $n=4$ in each pool) using the SOLiD version 2 sequencer [47]. We downloaded the pooled libraries from the DDBJ database (DDBJ accession number SRP005132). ncRNAs were downloaded from NONCODE version 3 [48] and a to- tal of 75,814 mouse piRNAs were extracted from this database. As the SOLiD reads correspond to the 5' ends of small RNAs, we directly mapped the respective reads from the pooled WT and KO libraries, using SHRiMP version 2.2.2 [49] with the default parameters, to the mouse piRNAs. After mapping we corrected tag numbers for reads multi-mapping to more than one piRNA, so that if a read mapped equally well to 2 or more individual piRNA sequences, the tag numbers were divided by the number of times it multi mapped, followed by equal assignment to all the piRNAs. For expression analysis we did not take into consideration multi mapped reads that mapped to 5 or more piRNAs and also filtered out reads that had less than 5 tags in the $\mathrm{KO}$ samples. The tag numbers were normalized by tags per million before comparison between wildtype and KO samples. Our very preliminary analysis of piRNAs in the cerebellum reveals 357 piRNAs in the cerebellum libraries (Supplementary Table 1). While 81\% (287) of the individual piRNAs found in the cerebellum have a higher expression in KO, 59\% (208) piRNAs show an expression change of over 1.5 fold in the KO cerebellum compared with the wildtype (Fig. 1B and supplementary Table 1). Overall, we found a striking 1.9 fold increase in the total piRNAs in the KO cerebellum in comparison with the wildtype cerebellum (Table 1 and Fig. 1A) suggesting a global increase in piRNAs in the Mecp2 KO sample. We next investigated whether the 20 most abundant piRNAs identified by Lee et al. in the mouse hippocampus were represented in the mouse cerebellum [46]. We found 19 out of the 20 piRNAs reported by Lee et al. in the cerebellum libraries (Table 2) including DQ 541777 (the piRNA implicated in regulating the size of dendritic spines) and of these, 12 piRNAs $(60 \%)$ revealed a fold change of over 1.5 in the KO cerebellum (Table 2). Interestingly, DQ541777 is the $5^{\text {th }}$ most abundant piRNA in the cerebellum libraries, the two most highly abundant piRNAs in the cerebellum libraries map to rRNA loci, which were incidentally excluded in the hippocampal analysis [46].

Based on our preliminary findings, we suggest a model for Rett Syndrome where, in the absence of a functional $\mathrm{MeCP} 2$, the over-expressed repeat elements lead to an increase in the total piRNAs. The overrepresented piRNAs may function, not only to deplete the load of repeat transcripts in cells, but also to finetune the expression level of specific genes. Thus piRNA mis-regulation may contribute to some of the differences in gene expression seen in the Mecp $2 \mathrm{KO}$ mouse brain.

While our analyses provide preliminary evidence of genome wide piRNA over-expression in the Mecp2 
Table 1

piRNA analysis in the short RNA libraries made from 6 week old pooled cerebellum from the wildtype mouse and the Mecp2 knockout mouse [38] (DDBJ accession number SRP005132)

\begin{tabular}{lcc}
\hline & WT cerebellum & KO cerebellum \\
\hline Read ID & SRR089647 & SRR089648 \\
Total sRNA reads & 3660124 & 2789136 \\
Total reads mapped to piRNAs (no filter) & 362089 & 522238 \\
Reads mapped to piRNAs (filter out $<$ reads in KO) & 356283 & 518589 \\
piRNA mapped tags normalized by TPM & 97341.74762 & 185931.8441 \\
Fold change (tpm normalized piRNAs over WT) & 1 & 1.910093548 \\
\hline
\end{tabular}

A

\section{Fold change in total piRNAs normalized to TPM}

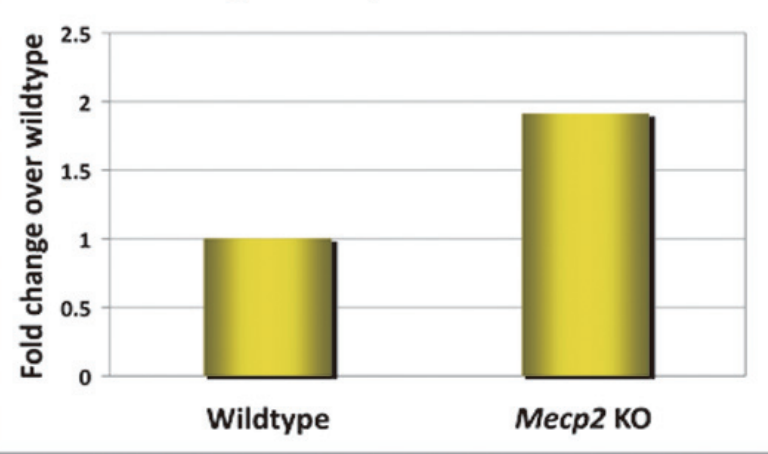

B

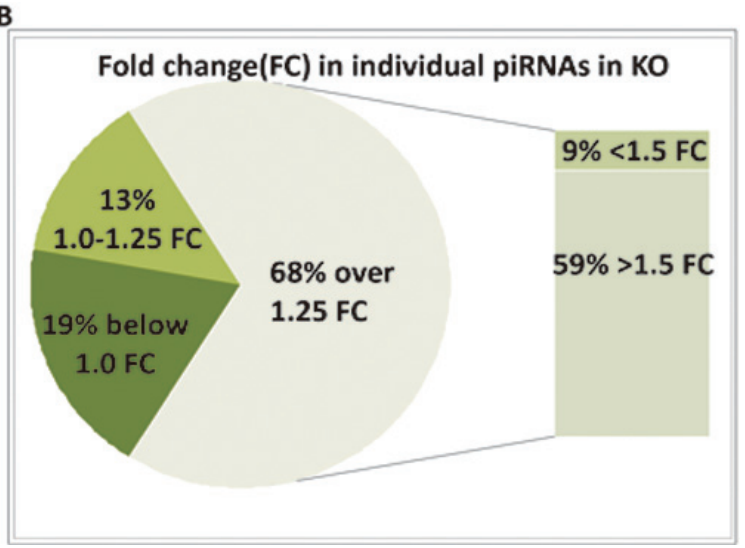

Fig. 1. piRNA levels are elevated in Mecp2 KO cerebellum. Read numbers for individual piRNAs found in the wildtype (WT) and Mecp2 knockout (KO) samples were normalized to tags per million as described in the text. After filtering out the piRNAs with less than 5 reads in the KO sample, the total piRNA reads were summed up. The histogram in panel A shows that the total numbers of piRNAs are almost doubled (1.9 fold) in the KO sample suggesting a global rise in piRNAs. The fold change relative to WT was calculated for each individual piRNA in KO. The pie chart in panel B reveals that $81 \%$ of piRNAs show a higher expression level in the KO sample. Of these, $59 \%$ have a fold change of over 1.5 in the KO sample (see supplementary Table 1). (Colours are visible in the online version of the article; http://dx.doi.org/10.3233/DMA-2012-0932)

KO cerebellum, this data was generated from libraries without replicates. Thus additional detailed investigations are warranted to affirm the over-representation of piRNAs and gain insights into the extent of their contribution to the gene mis-regulation seen in the Rett mouse model. We did not venture into the identification of gene targets of mis-regulated piRNAs and their intersection with the known mis-regulated genes or repeats. Such data may provide insights into the mis-regulation of some genes and the biogenesis of the over-represented piRNAs. Notably, in humans and mouse, an absence of $\mathrm{MeCP} 2$ results in fewer dendritic spines when compared with wildtype neurons [50,51]. While inhibition of DQ541777 was reported to cause a decrease in spine density, whether the overexpression of piRNAs, including DQ541777, can cause such morphological changes in the brain is not yet known. Further, recent reports have demonstrated that unlike mRNAs, miRNAs are stable in extracellular environments including blood serum [52,53]. Although such analyses have not been conducted for piRNAs, if piRNAs are found to be stable in extracellular fluids, differential- ly expressed piRNAs may potentially represent clinical biomarkers for the diagnosis and prognosis of Rett Syndrome.

There is overwhelming complexity in unravelling the molecular pathogenesis of the phenotype seen in Rett syndrome. Although the miRNA repertoire of Mecp 2 $\mathrm{KO}$ cerebellum has been investigated using next generation sequencing approaches, the field would benefit in re-identifying mis-regulated transcripts through deep, long and short (to identify sRNAs other than miRNAs), RNA sequencing of specific brain regions. Additionally, RC-seq conducted to identify somatic integration events would reveal whether the overexpressed genes are correlated with intronic LINE-1 insertion events. And while it has been established for the Mecp2 KO mouse model, that investigating a specific brain region is more fruitful than investigating the whole brain [26], analysis of neuronal subtypes would be even more insightful. Until now, the isolation of neuronal subtypes from adult mouse brain using high throughput techniques such as FACS sorting was challenging, yielding few nuclei and poor quality RNA. A recently pub- 
Table 2

Comparison of the top twenty piRNAs reported in the hippocampus [38] with the piRNAs found in the cerebellum

\begin{tabular}{lcccccc}
\hline $\begin{array}{l}\text { Top 20 piRNAs } \\
\text { in hippocampus }\end{array}$ & $\begin{array}{c}\text { WT hippocampus } \\
\text { tag numbers }\end{array}$ & $\begin{array}{c}\text { WT cerebellum } \\
\text { tag numbers }\end{array}$ & $\begin{array}{c}\text { KOcerebellum } \\
\text { tag numbers }\end{array}$ & $\begin{array}{c}\text { WT cerebellum } \\
\text { TPM }\end{array}$ & $\begin{array}{c}\text { KO cerebellum } \\
\text { TPM }\end{array}$ & $\begin{array}{c}\text { FC } \\
\text { KO/WT }\end{array}$ \\
\hline DQ541777 & 16130 & 1995.50 & 2411.00 & 545.20 & 864.43 & 1.59 \\
DQ705026 & 6257 & 154.00 & 377.00 & 42.08 & 135.17 & 3.21 \\
DQ555094 & 3439 & 202.00 & 140.00 & 55.19 & 50.19 & 0.91 \\
DQ719597 & 2459 & 168.00 & 306.00 & 45.90 & 109.71 & 2.39 \\
DQ689086 & 1514 & 65.00 & 78.00 & 17.76 & 27.97 & 1.57 \\
DQ540285 & 1433 & 457.40 & 548.23 & 124.97 & 196.56 & 1.57 \\
DQ540981 & 1360 & 126.50 & 124.00 & 34.56 & 44.46 & 1.29 \\
DQ720186 & 849 & 336.00 & 251.00 & 91.80 & 89.99 & 0.98 \\
DQ555093 & 775 & 189.50 & 129.50 & 51.77 & 46.43 & 0.90 \\
DQ540862 & 639 & 21.50 & 33.50 & 5.87 & 12.01 & 2.04 \\
DQ540284 & 635 & 456.90 & 548.23 & 124.83 & 196.56 & 1.57 \\
DQ541506 & 580 & 523.90 & 627.40 & 143.14 & 224.94 & 1.57 \\
DQ539915 & 304 & 35.50 & 28.00 & 9.70 & 10.04 & 1.04 \\
DQ540861 & 252 & 20.50 & 31.50 & 5.60 & 11.29 & 2.02 \\
DQ715526 & 207 & 20.00 & 20.00 & 5.46 & 7.17 & 1.31 \\
DQ543676 & 182 & 438.90 & 518.70 & 119.91 & 185.97 & 1.55 \\
DQ722288 & 175 & 2.00 & 13.00 & 0.55 & 4.66 & 8.53 \\
DQ551351 & 168 & Not found & Not found & Not found & Not found & Not found \\
DQ550765 & 118 & 10.75 & 9.50 & 2.94 & 3.41 & 1.16 \\
DQ708131 & 115 & 3.00 & 6.00 & 0.82 & 2.15 & 2.62 \\
\hline
\end{tabular}

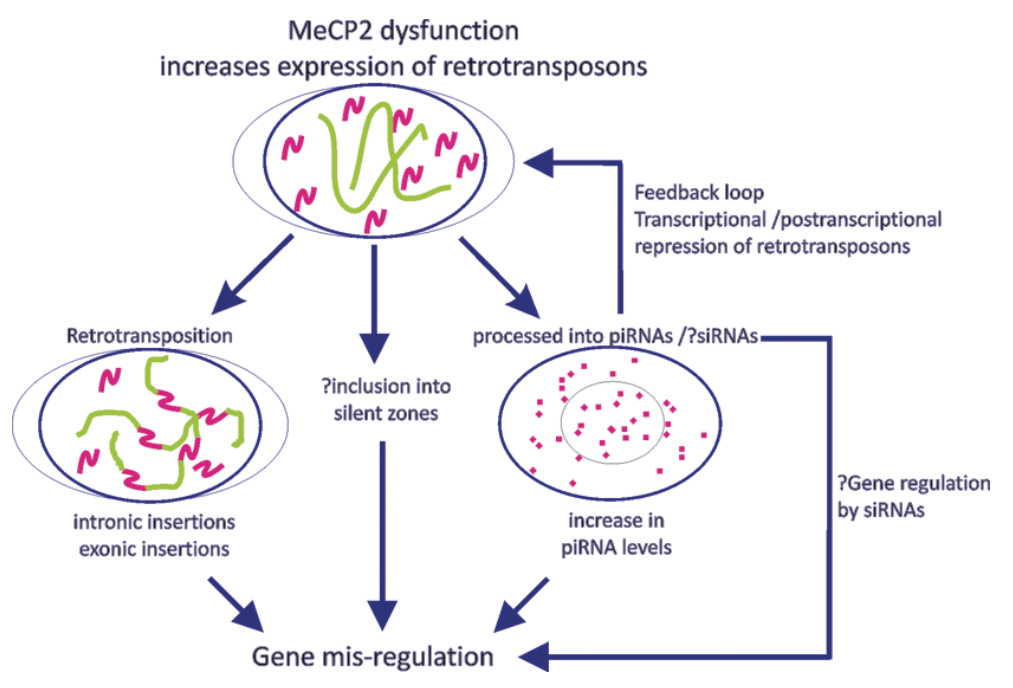

Fig. 2. Schematic of the proposed model showing that changes in the expression level of some genes may be a consequence of the increase in expression of retrotransposons. DNA is depicted in green, retrotransposon transcripts in pink and piRNAs as pink dots. See text for details. (Colours are visible in the online version of the article; http://dx.doi.org/10.3233/DMA-2012-0932)

lished trehalose enhanced technique for FACS sorting individual neuronal subtypes could help isolate high quality RNA from Mecp 2 null neuronal subtypes for transcriptome sequencing [54].

In conclusion, we propose that overexpression of LINE-1 may contribute to the mis-regulation of some genes in Rett syndrome, mediated through insertional events or by an increase in piRNAs (Fig. 2). Our preliminary data suggests that piRNA expression levels may be altered globally in the absence of MeCP2. Appli- cation of next generation sequencing technologies may resolve some key questions regarding MeCP2 function and the downstream consequences of a dysfunctional $\mathrm{MeCP} 2$.

\section{Acknowledgements}

A.S. is supported by the Funding Program for Next Generation World-Leading Researchers by MEXT to 
P.C and a MEXT Grant-in-Aid 321-EA-O-77; D.T. is supported by the European Union 7th Framework Programme under grant agreement FP7-People-ITN-2008238055 ("BrainTrain" project) to P.C. and a Research Grant for RIKEN Omics Science Center from MEXT.

\section{References}

[1] Amir, R.E., et al., Rett syndrome is caused by mutations in $\mathrm{X}$-linked MECP2, encoding methyl-CpG-binding protein 2. Nat Genet, 1999. 23(2): 185-8.

[2] Weaving, L.S., et al., Mutations of CDKL5 cause a severe neurodevelopmental disorder with infantile spasms and mental retardation. Am J Hum Genet, 2004. 75(6): 1079-93.

[3] Ariani, F., et al., FOXG1 is responsible for the congenital variant of Rett syndrome. Am J Hum Genet, 2008. 83(1): 89-93.

[4] Neul, J.L., et al., Rett syndrome: revised diagnostic criteria and nomenclature. Ann Neurol, 2010. 68(6): 944-50.

[5] Adler, D.A., et al., The X-linked methylated DNA binding protein, Mecp2, is subject to $\mathrm{X}$ inactivation in the mouse. Mamm Genome, 1995. 6(8): p. 491-2.

[6] Chaumeil, J., et al., A novel role for Xist RNA in the formation of a repressive nuclear compartment into which genes are recruited when silenced. Genes Dev, 2006. 20(16): 2223-37.

[7] Carrel, L. and H.F. Willard, X-inactivation profile reveals extensive variability in $\mathrm{X}$-linked gene expression in females. Nature, 2005. 434(7031): 400-4.

[8] Lingenfelter, P.A., et al., Escape from X inactivation of Smcx is preceded by silencing during mouse development. Nat Genet, 1998. 18(3): 212-3.

[9] Xu, J., X. Deng and C.M. Disteche, Sex-specific expression of the X-linked histone demethylase gene Jarid1c in brain. PLoS One, 2008. 3(7): e2553.

[10] Yang, F., et al., Global survey of escape from X inactivation by RNA-sequencing in mouse. Genome Res, 2010. 20(5): 61422.

[11] Hoffbuhr, K.C., et al., Associations between MeCP2 mutations, X-chromosome inactivation, and phenotype. Ment Retard Dev Disabil Res Rev, 2002. 8(2): 99-105.

[12] Weaving, L.S., et al., Effects of MECP2 mutation type, location and $\mathrm{X}$-inactivation in modulating Rett syndrome phenotype. Am J Med Genet A, 2003. 118A(2): 103-14.

[13] Huppke, P., et al., Very mild cases of Rett syndrome with skewed X inactivation. J Med Genet, 2006. 43(10): 814-6.

[14] Xinhua, B., et al., X chromosome inactivation in Rett Syndrome and its correlations with MECP2 mutations and phenotype. J Child Neurol, 2008. 23(1): 22-5.

[15] Kriaucionis, S. and A. Bird, The major form of MeCP2 has a novel N-terminus generated by alternative splicing. Nucleic Acids Res, 2004. 32(5): 1818-23.

[16] Mnatzakanian, G.N., et al., A previously unidentified MECP2 open reading frame defines a new protein isoform relevant to Rett syndrome. Nat Genet, 2004. 36(4): 339-41.

[17] Saxena, A., et al., Lost in translation: translational interference from a recurrent mutation in exon 1 of MECP2. J Med Genet, 2006. 43(6): 470-7.

[18] Gianakopoulos, P.J., et al., Mutations in MECP2 exon 1 in classical Rett patients disrupt MECP2_e1 transcription, but not transcription of MECP2_e2. Am J Med Genet B Neuropsychiatr Genet, 2012. 159B(2): 210-6.
[19] Nan, X., et al., Transcriptional repression by the methyl-CpGbinding protein $\mathrm{MeCP} 2$ involves a histone deacetylase complex. Nature, 1998. 393(6683): 386-9.

[20] Jones, P.L., et al., Methylated DNA and MeCP2 recruit histone deacetylase to repress transcription. Nat Genet, 1998. 19(2): 187-91.

[21] Georgel, P.T., et al., Chromatin compaction by human MeCP2. Assembly of novel secondary chromatin structures in the absence of DNA methylation. J Biol Chem, 2003. 278(34): 32181-8.

[22] Nikitina, T., et al., Multiple modes of interaction between the methylated DNA binding protein $\mathrm{MeCP} 2$ and chromatin. Mol Cell Biol, 2007. 27(3): 864-77.

[23] Shahbazian, M., et al., Mice with truncated MeCP2 recapitulate many Rett syndrome features and display hyperacetylation of histone H3. Neuron, 2002. 35(2): 243-54.

[24] Skene, P.J., et al., Neuronal MeCP2 is expressed at near histone-octamer levels and globally alters the chromatin state. Mol Cell, 2010. 37(4): 457-68.

[25] Yasui, D.H., et al., Integrated epigenomic analyses of neuronal $\mathrm{MeCP} 2$ reveal a role for long-range interaction with active genes. Proc Natl Acad Sci U S A, 2007. 104(49): 19416-21.

[26] Chahrour, M., et al., MeCP2, a key contributor to neurological disease, activates and represses transcription. Science, 2008. 320(5880): 1224-9.

[27] Urdinguio, R.G., et al., Mecp2-null mice provide new neuronal targets for Rett syndrome. PLoS One, 2008. 3(11): e3669.

[28] Yakabe, S., et al., MeCP2 knockdown reveals DNA methylation-independent gene repression of target genes in living cells and a bias in the cellular location of target gene products. Genes Genet Syst, 2008. 83(2): 199-208.

[29] Smrt, R.D., et al., Mecp2 deficiency leads to delayed maturation and altered gene expression in hippocampal neurons. Neurobiol Dis, 2007. 27(1): 77-89.

[30] Yu, F., et al., Methyl-CpG-binding protein 2 represses LINE1 expression and retrotransposition but not Alu transcription. Nucleic Acids Res, 2001. 29(21): 4493-501.

[31] Muotri, A.R., et al., L1 retrotransposition in neurons is modulated by MeCP2. Nature, 2010. 468(7322): 443-6.

[32] Saxena, A. and P. Carninci, Long non-coding RNA modifies chromatin: epigenetic silencing by long non-coding RNAs. Bioessays, 2011. 33(11): 830-9.

[33] Chow, J.C., et al., LINE-1 activity in facultative heterochromatin formation during $\mathrm{X}$ chromosome inactivation. Cell, 2010. 141(6): 956-69.

[34] Djebali S, et al., Landscape of transcription in human cells. Nature, 2012. doi:10.1038/nature11233.

[35] Baillie, J.K., et al., Somatic retrotransposition alters the genetic landscape of the human brain. Nature, 2011. 479(7374): 534-7.

[36] Slotkin, R.K. and R. Martienssen, Transposable elements and the epigenetic regulation of the genome. Nat Rev Genet, 2007. 8(4): 272-85.

[37] Yang, N. and H.H. Kazazian, Jr., L1 retrotransposition is suppressed by endogenously encoded small interfering RNAs in human cultured cells. Nat Struct Mol Biol, 2006. 13(9): 76371.

[38] Watanabe, T., et al., Endogenous siRNAs from naturally formed dsRNAs regulate transcripts in mouse oocytes. Nature, 2008. 453(7194): 539-43.

[39] Aravin, A., et al., A novel class of small RNAs bind to MILI protein in mouse testes. Nature, 2006. 442(7099): 203-7.

[40] Girard, A., et al., A germline-specific class of small RNAs 
binds mammalian Piwi proteins. Nature, 2006. 442 (7099): 199-202.

[41] Chen, L., et al., Naturally occurring endo-siRNA silences LINE-1 retrotransposons in human cells through DNA methylation. Epigenetics, 2012. 7(7): 758-71.

[42] Reuter, M., et al., Miwi catalysis is required for piRNA amplification-independent LINE1 transposon silencing. Nature, 2011. 480(7376): 264-7.

[43] Watanabe, T., et al., Role for piRNAs and noncoding RNA in de novo DNA methylation of the imprinted mouse Rasgrf1 locus. Science, 2011. 332(6031): 848-52.

[44] Brennecke, J., et al., Discrete small RNA-generating loci as master regulators of transposon activity in Drosophila. Cell, 2007. 128(6): 1089-103.

[45] Gunawardane, L.S., et al., A slicer-mediated mechanism for repeat-associated siRNA 5' end formation in Drosophila. Science, 2007. 315(5818): 1587-90.

[46] Lee, E.J., et al., Identification of piRNAs in the central nervous system. RNA, 2011. 17(6): 1090-9.

[47] Wu, H., et al., Genome-wide analysis reveals methyl-CpGbinding protein 2-dependent regulation of microRNAs in a mouse model of Rett syndrome. Proc Natl Acad Sci U S A, 2010. 107(42): 18161-6.
[48] $\mathrm{Bu}, \mathrm{D}$., et al., NONCODE v3.0: integrative annotation of long noncoding RNAs. Nucleic Acids Res, 2012. 40 (Database issue): D210-5.

[49] David, M., et al., SHRiMP2: sensitive yet practical SHort Read Mapping. Bioinformatics, 2011. 27(7): 1011-2.

[50] Belichenko, P.V., et al., Widespread changes in dendritic and axonal morphology in Mecp2-mutant mouse models of Rett syndrome: evidence for disruption of neuronal networks. J Comp Neurol, 2009. 514(3): 240-58.

[51] Chapleau, C.A., et al., Dendritic spine pathologies in hippocampal pyramidal neurons from Rett syndrome brain and after expression of Rett-associated MECP2 mutations. Neurobiol Dis, 2009. 35(2): 219-33.

[52] Wang, K., et al., Export of microRNAs and microRNAprotective protein by mammalian cells. Nucleic Acids Res, 2010. 38(20): 7248-59.

[53] Turchinovich, A., et al., Characterization of extracellular circulating microRNA. Nucleic Acids Res, 2011. 39(16): 722333.

[54] Saxena, A., et al., Trehalose-enhanced isolation of neuronal sub-types from adult mouse brain. Biotechniques, 2012. 52(6): $381-5$. 


\section{Supplemental material}

Supplementary Table 1

List of piRNAs, found in the cerebellum samples in wildtype and Mecp2 KO samples with their tag numbers and normalized tags per million (Tpm) values. This list was generated after filtering out piRNAs with less than 5 tags in the Mecp2 KO sample. Top 20 piRNAs reported to be present in the hippocampus [38] are highlighted in bold. Tpm was calculated by dividing the tag numbers by the total number of reads in the library (see Table 1, 3660124 for wildtype (WT) and 2789136 for Mecp2 KO). Fold change was calculated by dividing the Tpm normalized tag numbers for Mecp2 KO with WT

\begin{tabular}{|c|c|c|c|c|c|c|c|}
\hline $\begin{array}{l}\text { piRNA } \\
\text { accession }\end{array}$ & Length & $\begin{array}{c}\text { Number of tags in } \\
\text { wildtype cerebellum }\end{array}$ & $\begin{array}{c}\text { Number of tags in } \\
\text { Mecp2 KO cerebellum }\end{array}$ & WT_Tpm & $\begin{array}{c}\text { Mecp2 } \\
\text { KO_Tpm }\end{array}$ & $\begin{array}{c}\text { Fold_change_ } \\
\text { KO/WT }\end{array}$ & $\begin{array}{c}\text { Reported as top } \\
20 \text { piRNAs in brain }\end{array}$ \\
\hline DQ546606 & 29 & 147865.67 & 229912.17 & 40399.09 & 82431.32 & 2.04 & No \\
\hline DQ540966 & 30 & 146001.83 & 228493.17 & 39889.86 & 81922.56 & 2.05 & No \\
\hline DQ540188 & 25 & 29252.92 & 24557.00 & 7992.33 & 8804.52 & 1.10 & No \\
\hline DQ558990 & 30 & 6166.50 & 11048.00 & 1684.78 & 3961.08 & 2.35 & No \\
\hline DQ541777 & 30 & 1995.50 & 2411.00 & 545.20 & 864.43 & 1.59 & Yes \\
\hline DQ703900 & 32 & 4252.00 & 1621.50 & 1161.71 & 581.36 & 0.50 & No \\
\hline DQ540229 & 31 & 1495.50 & 1033.33 & 408.59 & 370.49 & 0.91 & No \\
\hline DQ719271 & 21 & 1355.00 & 1009.83 & 370.21 & 362.06 & 0.98 & No \\
\hline DQ540053 & 29 & 810.00 & 822.00 & 221.30 & 294.71 & 1.33 & No \\
\hline DQ708952 & 22 & 694.00 & 720.00 & 189.61 & 258.14 & 1.36 & No \\
\hline DQ541506 & 28 & 523.90 & 627.40 & 143.14 & 224.94 & 1.57 & Yes \\
\hline DQ542358 & 31 & 446.00 & 549.50 & 121.85 & 197.01 & 1.62 & No \\
\hline DQ540285 & 32 & 457.40 & 548.23 & 124.97 & 196.56 & 1.57 & Yes \\
\hline DQ540284 & 31 & 456.90 & 548.23 & 124.83 & 196.56 & 1.57 & Yes \\
\hline DQ540283 & 31 & 456.90 & 548.23 & 124.83 & 196.56 & 1.57 & No \\
\hline DQ543676 & 31 & 438.90 & 518.70 & 119.91 & 185.97 & 1.55 & Yes \\
\hline DQ701563 & 26 & 384.00 & 489.50 & 104.91 & 175.50 & 1.67 & No \\
\hline DQ541630 & 25 & 680.50 & 464.00 & 185.92 & 166.36 & 0.89 & No \\
\hline DQ705026 & 29 & 154.00 & 377.00 & 42.08 & 135.17 & 3.21 & Yes \\
\hline DQ551624 & 28 & 196.00 & 349.33 & 53.55 & 125.25 & 2.34 & No \\
\hline DQ551625 & 29 & 196.00 & 349.33 & 53.55 & 125.25 & 2.34 & No \\
\hline DQ701020 & 19 & 281.00 & 339.00 & 76.77 & 121.54 & 1.58 & No \\
\hline DQ715971 & 25 & 461.17 & 327.00 & 126.00 & 117.24 & 0.93 & No \\
\hline DQ710909 & 23 & 428.17 & 312.00 & 116.98 & 111.86 & 0.96 & No \\
\hline DQ719597 & 28 & 168.00 & 306.00 & 45.90 & 109.71 & 2.39 & Yes \\
\hline $\mathrm{n} 200793$ & 31 & 463.83 & 302.50 & 126.73 & 108.46 & 0.86 & No \\
\hline DQ711996 & 22 & 313.83 & 295.00 & 85.74 & 105.77 & 1.23 & No \\
\hline DQ724236 & 18 & 264.83 & 277.00 & 72.36 & 99.31 & 1.37 & No \\
\hline DQ541689 & 30 & 401.30 & 273.15 & 109.64 & 97.93 & 0.89 & No \\
\hline DQ720186 & 23 & 336.00 & 251.00 & 91.80 & 89.99 & 0.98 & Yes \\
\hline DQ714752 & 31 & 115.30 & 242.15 & 31.50 & 86.82 & 2.76 & No \\
\hline DQ559312 & 26 & 380.00 & 224.00 & 103.82 & 80.31 & 0.77 & No \\
\hline n202644 & 19 & 173.00 & 222.50 & 47.27 & 79.77 & 1.69 & No \\
\hline DQ725273 & 26 & 335.80 & 221.70 & 91.75 & 79.49 & 0.87 & No \\
\hline n204765 & 21 & 145.00 & 210.17 & 39.62 & 75.35 & 1.90 & No \\
\hline DQ558144 & 25 & 376.00 & 209.00 & 102.73 & 74.93 & 0.73 & No \\
\hline DQ696996 & 22 & 206.50 & 192.00 & 56.42 & 68.84 & 1.22 & No \\
\hline DQ707524 & 20 & 191.50 & 191.00 & 52.32 & 68.48 & 1.31 & No \\
\hline DQ553318 & 26 & 181.00 & 163.00 & 49.45 & 58.44 & 1.18 & No \\
\hline DQ714439 & 28 & 178.47 & 147.18 & 48.76 & 52.77 & 1.08 & No \\
\hline DQ555094 & 32 & 202.00 & 140.00 & 55.19 & 50.19 & 0.91 & Yes \\
\hline DQ716505 & 21 & 80.25 & 138.50 & 21.93 & 49.66 & 2.26 & No \\
\hline DQ719430 & 23 & 79.25 & 137.00 & 21.65 & 49.12 & 2.27 & No \\
\hline DQ706273 & 22 & 79.25 & 137.00 & 21.65 & 49.12 & 2.27 & No \\
\hline DQ712837 & 23 & 53.00 & 135.00 & 14.48 & 48.40 & 3.34 & No \\
\hline DQ549760 & 29 & 191.00 & 133.00 & 52.18 & 47.69 & 0.91 & No \\
\hline DQ555093 & 29 & 189.50 & 129.50 & 51.77 & 46.43 & 0.90 & Yes \\
\hline DQ550329 & 28 & 126.00 & 127.00 & 34.43 & 45.53 & 1.32 & No \\
\hline DQ540952 & 28 & 91.70 & 124.27 & 25.05 & 44.55 & 1.78 & No \\
\hline DQ540981 & 30 & 126.50 & 124.00 & 34.56 & 44.46 & 1.29 & Yes \\
\hline DQ709462 & 30 & 90.67 & 108.33 & 24.77 & 38.84 & 1.57 & No \\
\hline
\end{tabular}


Supplementary Table 1, continued

\begin{tabular}{|c|c|c|c|c|c|c|c|}
\hline $\begin{array}{l}\text { piRNA } \\
\text { accession }\end{array}$ & Length & $\begin{array}{l}\text { Number of tags in } \\
\text { wildtype cerebellum }\end{array}$ & $\begin{array}{c}\text { Number of tags in } \\
\text { Mecp2 KO cerebellum }\end{array}$ & WT_Tpm & $\begin{array}{c}\text { Mecp2 } \\
\text { KO_Tpm }\end{array}$ & $\begin{array}{c}\text { Fold_change_ } \\
\text { KO/WT }\end{array}$ & $\begin{array}{c}\text { Reported as top } \\
20 \text { piRNAs in brain }\end{array}$ \\
\hline DQ540984 & 30 & 62.93 & 103.50 & 17.19 & 37.11 & 2.16 & No \\
\hline DQ713872 & 22 & 81.00 & 97.00 & 22.13 & 34.78 & 1.57 & No \\
\hline DQ552696 & 30 & 120.00 & 91.00 & 32.79 & 32.63 & 1.00 & No \\
\hline DQ719488 & 24 & 248.00 & 90.00 & 67.76 & 32.27 & 0.48 & No \\
\hline DQ541470 & 27 & 127.72 & 89.05 & 34.89 & 31.93 & 0.91 & No \\
\hline DQ551913 & 27 & 57.33 & 80.25 & 15.66 & 28.77 & 1.84 & No \\
\hline DQ689086 & 27 & 65.00 & 78.00 & 17.76 & 27.97 & 1.57 & Yes \\
\hline DQ717385 & 22 & 89.50 & 64.33 & 24.45 & 23.07 & 0.94 & No \\
\hline DQ548183 & 28 & 65.50 & 60.00 & 17.90 & 21.51 & 1.20 & No \\
\hline DQ540859 & 30 & 77.50 & 58.50 & 21.17 & 20.97 & 0.99 & No \\
\hline DQ556354 & 30 & 20.00 & 58.50 & 5.46 & 20.97 & 3.84 & No \\
\hline DQ696831 & 31 & 33.00 & 54.00 & 9.02 & 19.36 & 2.15 & No \\
\hline DQ540872 & 32 & 107.50 & 54.00 & 29.37 & 19.36 & 0.66 & No \\
\hline DQ540944 & 26 & 47.68 & 53.08 & 13.03 & 19.03 & 1.46 & No \\
\hline DQ542796 & 28 & 49.00 & 53.00 & 13.39 & 19.00 & 1.42 & No \\
\hline DQ546708 & 30 & 43.00 & 52.00 & 11.75 & 18.64 & 1.59 & No \\
\hline DQ541352 & 25 & 44.93 & 51.08 & 12.28 & 18.32 & 1.49 & No \\
\hline DQ540974 & 29 & 66.50 & 49.50 & 18.17 & 17.75 & 0.98 & No \\
\hline DQ540526 & 28 & 32.00 & 49.00 & 8.74 & 17.57 & 2.01 & No \\
\hline DQ551739 & 28 & 22.67 & 47.22 & 6.19 & 16.93 & 2.73 & No \\
\hline DQ540403 & 30 & 24.00 & 46.00 & 6.56 & 16.49 & 2.52 & No \\
\hline DQ540915 & 30 & 54.00 & 46.00 & 14.75 & 16.49 & 1.12 & No \\
\hline DQ539904 & 28 & 45.00 & 45.50 & 12.29 & 16.31 & 1.33 & No \\
\hline DQ699095 & 24 & 20.00 & 44.50 & 5.46 & 15.95 & 2.92 & No \\
\hline DQ723924 & 20 & 20.00 & 44.00 & 5.46 & 15.78 & 2.89 & No \\
\hline DQ541614 & 28 & 18.38 & 43.58 & 5.02 & 15.63 & 3.11 & No \\
\hline DQ564913 & 30 & 29.33 & 41.92 & 8.01 & 15.03 & 1.88 & No \\
\hline DQ553409 & 27 & 45.50 & 41.50 & 12.43 & 14.88 & 1.20 & No \\
\hline DQ547181 & 28 & 18.00 & 41.00 & 4.92 & 14.70 & 2.99 & No \\
\hline DQ545450 & 28 & 32.00 & 41.00 & 8.74 & 14.70 & 1.68 & No \\
\hline DQ687520 & 26 & 41.93 & 39.08 & 11.46 & 14.01 & 1.22 & No \\
\hline DQ689768 & 30 & 26.00 & 39.00 & 7.10 & 13.98 & 1.97 & No \\
\hline DQ540964 & 25 & 42.50 & 39.00 & 11.61 & 13.98 & 1.20 & No \\
\hline DQ701846 & 29 & 46.00 & 38.00 & 12.57 & 13.62 & 1.08 & No \\
\hline DQ540058 & 27 & 17.00 & 37.00 & 4.64 & 13.27 & 2.86 & No \\
\hline DQ706530 & 31 & 34.00 & 36.17 & 9.29 & 12.97 & 1.40 & No \\
\hline DQ710928 & 30 & 54.00 & 36.00 & 14.75 & 12.91 & 0.87 & No \\
\hline DQ706818 & 28 & 52.00 & 36.00 & 14.21 & 12.91 & 0.91 & No \\
\hline DQ546549 & 25 & 33.83 & 36.00 & 9.24 & 12.91 & 1.40 & No \\
\hline DQ540988 & 28 & 23.17 & 35.50 & 6.33 & 12.73 & 2.01 & No \\
\hline DQ540862 & 30 & 21.50 & 33.50 & 5.87 & 12.01 & 2.04 & Yes \\
\hline DQ696491 & 29 & 41.72 & 32.92 & 11.40 & 11.80 & 1.04 & No \\
\hline DQ540861 & 27 & 20.50 & 31.50 & 5.60 & 11.29 & 2.02 & Yes \\
\hline DQ563946 & 30 & 5.00 & 31.00 & 1.37 & 11.11 & 8.14 & No \\
\hline DQ562907 & 29 & 9.73 & 30.70 & 2.66 & 11.01 & 4.14 & No \\
\hline DQ702901 & 29 & 13.00 & 30.67 & 3.55 & 11.00 & 3.10 & No \\
\hline DQ707624 & 26 & 14.93 & 30.07 & 4.08 & 10.78 & 2.64 & No \\
\hline DQ540780 & 26 & 16.33 & 30.00 & 4.46 & 10.76 & 2.41 & No \\
\hline DQ540412 & 27 & 37.00 & 29.00 & 10.11 & 10.40 & 1.03 & No \\
\hline DQ539915 & 32 & 35.50 & 28.00 & 9.70 & 10.04 & 1.04 & Yes \\
\hline DQ565590 & 31 & 1.00 & 28.00 & 0.27 & 10.04 & 36.74 & No \\
\hline DQ698557 & 30 & 10.93 & 27.65 & 2.99 & 9.91 & 3.32 & No \\
\hline DQ689686 & 22 & 28.75 & 27.50 & 7.85 & 9.86 & 1.26 & No \\
\hline DQ541113 & 31 & 15.50 & 27.50 & 4.23 & 9.86 & 2.33 & No \\
\hline DQ555883 & 30 & 59.75 & 27.30 & 16.32 & 9.79 & 0.60 & No \\
\hline DQ711586 & 30 & 27.00 & 27.00 & 7.38 & 9.68 & 1.31 & No \\
\hline DQ564866 & 27 & 14.83 & 27.00 & 4.05 & 9.68 & 2.39 & No \\
\hline DQ562906 & 27 & 8.73 & 26.70 & 2.39 & 9.57 & 4.01 & No \\
\hline
\end{tabular}


Supplementary Table 1, continued

\begin{tabular}{|c|c|c|c|c|c|c|c|}
\hline $\begin{array}{l}\text { piRNA } \\
\text { accession }\end{array}$ & Length & $\begin{array}{c}\text { Number of tags in } \\
\text { wildtype cerebellum }\end{array}$ & $\begin{array}{c}\text { Number of tags in } \\
\text { Mecp2 KO cerebellum }\end{array}$ & WT_Tpm & $\begin{array}{c}\text { Mecp2 } \\
\text { KO_Tpm } \\
\end{array}$ & $\begin{array}{c}\text { Fold_change_ } \\
\text { KO/WT }\end{array}$ & $\begin{array}{c}\text { Reported as top } \\
20 \text { piRNAs in brain }\end{array}$ \\
\hline DQ564777 & 27 & 11.00 & 26.70 & 3.01 & 9.57 & 3.19 & No \\
\hline DQ562139 & 27 & 29.00 & 26.00 & 7.92 & 9.32 & 1.18 & No \\
\hline DQ725665 & 32 & 27.67 & 26.00 & 7.56 & 9.32 & 1.23 & No \\
\hline n205237 & 30 & 28.17 & 25.50 & 7.70 & 9.14 & 1.19 & No \\
\hline DQ702517 & 30 & 76.58 & 25.33 & 20.92 & 9.08 & 0.43 & No \\
\hline DQ725422 & 27 & 22.50 & 25.00 & 6.15 & 8.96 & 1.46 & No \\
\hline DQ540976 & 27 & 41.50 & 24.30 & 11.34 & 8.71 & 0.77 & No \\
\hline DQ564776 & 26 & 8.00 & 24.20 & 2.19 & 8.68 & 3.97 & No \\
\hline DQ709768 & 28 & 7.00 & 24.00 & 1.91 & 8.60 & 4.50 & No \\
\hline DQ540175 & 32 & 42.00 & 24.00 & 11.48 & 8.60 & 0.75 & No \\
\hline DQ540963 & 29 & 21.32 & 23.83 & 5.82 & 8.55 & 1.47 & No \\
\hline DQ691499 & 30 & 41.00 & 23.50 & 11.20 & 8.43 & 0.75 & No \\
\hline DQ701440 & 28 & 14.00 & 23.00 & 3.83 & 8.25 & 2.16 & No \\
\hline DQ539926 & 27 & 17.00 & 22.50 & 4.64 & 8.07 & 1.74 & No \\
\hline DQ724091 & 30 & 17.00 & 22.50 & 4.64 & 8.07 & 1.74 & No \\
\hline DQ715990 & 30 & 18.33 & 22.17 & 5.01 & 7.95 & 1.59 & No \\
\hline DQ719178 & 29 & 21.50 & 22.00 & 5.87 & 7.89 & 1.34 & No \\
\hline DQ687463 & 26 & 17.00 & 22.00 & 4.64 & 7.89 & 1.70 & No \\
\hline DQ552936 & 30 & 57.00 & 22.00 & 15.57 & 7.89 & 0.51 & No \\
\hline DQ703911 & 30 & 14.00 & 22.00 & 3.83 & 7.89 & 2.06 & No \\
\hline DQ555802 & 28 & 19.00 & 22.00 & 5.19 & 7.89 & 1.52 & No \\
\hline DQ540860 & 30 & 35.00 & 22.00 & 9.56 & 7.89 & 0.82 & No \\
\hline DQ707092 & 26 & 7.93 & 21.65 & 2.17 & 7.76 & 3.58 & No \\
\hline DQ555882 & 29 & 53.75 & 21.30 & 14.69 & 7.64 & 0.52 & No \\
\hline DQ721541 & 28 & 16.33 & 21.17 & 4.46 & 7.59 & 1.70 & No \\
\hline DQ715697 & 31 & 16.33 & 21.17 & 4.46 & 7.59 & 1.70 & No \\
\hline n199527 & 26 & 17.33 & 21.00 & 4.74 & 7.53 & 1.59 & No \\
\hline DQ709916 & 25 & 11.00 & 21.00 & 3.01 & 7.53 & 2.51 & No \\
\hline DQ565303 & 30 & 11.30 & 20.82 & 3.09 & 7.46 & 2.42 & No \\
\hline DQ718173 & 30 & 11.30 & 20.82 & 3.09 & 7.46 & 2.42 & No \\
\hline DQ692434 & 29 & 11.30 & 20.82 & 3.09 & 7.46 & 2.42 & No \\
\hline DQ691288 & 24 & 20.92 & 20.50 & 5.71 & 7.35 & 1.29 & No \\
\hline n199120 & 16 & 38.00 & 20.50 & 10.38 & 7.35 & 0.71 & No \\
\hline DQ715526 & 28 & 20.00 & 20.00 & 5.46 & 7.17 & 1.31 & Yes \\
\hline DQ567738 & 29 & 8.00 & 20.00 & 2.19 & 7.17 & 3.28 & No \\
\hline DQ720914 & 31 & 15.00 & 20.00 & 4.10 & 7.17 & 1.75 & No \\
\hline DQ540280 & 30 & 14.50 & 20.00 & 3.96 & 7.17 & 1.81 & No \\
\hline DQ540869 & 29 & 16.52 & 19.93 & 4.51 & 7.15 & 1.58 & No \\
\hline DQ540975 & 26 & 27.50 & 19.50 & 7.51 & 6.99 & 0.93 & No \\
\hline DQ541100 & 28 & 15.50 & 19.00 & 4.23 & 6.81 & 1.61 & No \\
\hline DQ712821 & 24 & 21.00 & 19.00 & 5.74 & 6.81 & 1.19 & No \\
\hline DQ545972 & 30 & 19.00 & 19.00 & 5.19 & 6.81 & 1.31 & No \\
\hline DQ702126 & 29 & 18.15 & 18.25 & 4.96 & 6.54 & 1.32 & No \\
\hline DQ703459 & 30 & 13.00 & 18.17 & 3.55 & 6.51 & 1.83 & No \\
\hline DQ699219 & 30 & 21.00 & 18.00 & 5.74 & 6.45 & 1.12 & No \\
\hline DQ540965 & 32 & 15.17 & 18.00 & 4.14 & 6.45 & 1.56 & No \\
\hline DQ707037 & 28 & 8.55 & 17.60 & 2.34 & 6.31 & 2.70 & No \\
\hline DQ541147 & 28 & 10.50 & 17.50 & 2.87 & 6.27 & 2.19 & No \\
\hline DQ555881 & 28 & 43.25 & 17.30 & 11.82 & 6.20 & 0.52 & No \\
\hline DQ568996 & 31 & 7.00 & 17.00 & 1.91 & 6.10 & 3.19 & No \\
\hline n202030 & 32 & 11.67 & 17.00 & 3.19 & 6.10 & 1.91 & No \\
\hline DQ703779 & 25 & 7.00 & 17.00 & 1.91 & 6.10 & 3.19 & No \\
\hline DQ545225 & 30 & 5.00 & 17.00 & 1.37 & 6.10 & 4.46 & No \\
\hline DQ541000 & 28 & 13.18 & 16.93 & 3.60 & 6.07 & 1.69 & No \\
\hline n197343 & 38 & 13.00 & 16.50 & 3.55 & 5.92 & 1.67 & No \\
\hline DQ540868 & 26 & 13.18 & 16.10 & 3.60 & 5.77 & 1.60 & No \\
\hline DQ541218 & 26 & 79.00 & 16.00 & 21.58 & 5.74 & 0.27 & No \\
\hline DQ718197 & 27 & 10.50 & 16.00 & 2.87 & 5.74 & 2.00 & No \\
\hline
\end{tabular}


Supplementary Table 1, continued

\begin{tabular}{|c|c|c|c|c|c|c|c|}
\hline $\begin{array}{l}\text { piRNA } \\
\text { accession }\end{array}$ & Length & $\begin{array}{c}\text { Number of tags in } \\
\text { wildtype cerebellum }\end{array}$ & $\begin{array}{c}\text { Number of tags in } \\
\text { Mecp2 KO cerebellum }\end{array}$ & WT_Tpm & $\begin{array}{c}\text { Mecp2 } \\
\text { KO_Tpm }\end{array}$ & $\begin{array}{c}\text { Fold_change_ } \\
\text { KO/WT }\end{array}$ & $\begin{array}{c}\text { Reported as top } \\
20 \text { piRNAs in brain }\end{array}$ \\
\hline DQ714526 & 30 & 18.07 & 15.67 & 4.94 & 5.62 & 1.14 & No \\
\hline DQ540689 & 29 & 29.50 & 15.50 & 8.06 & 5.56 & 0.69 & No \\
\hline DQ540059 & 26 & 11.00 & 15.50 & 3.01 & 5.56 & 1.85 & No \\
\hline DQ724251 & 22 & 11.75 & 15.40 & 3.21 & 5.52 & 1.72 & No \\
\hline DQ714788 & 30 & 26.50 & 15.33 & 7.24 & 5.50 & 0.76 & No \\
\hline DQ540867 & 25 & 11.93 & 15.10 & 3.26 & 5.41 & 1.66 & No \\
\hline DQ693545 & 30 & 4.67 & 15.00 & 1.28 & 5.38 & 4.22 & No \\
\hline DQ717257 & 29 & 17.00 & 14.50 & 4.64 & 5.20 & 1.12 & No \\
\hline DQ544489 & 29 & 8.92 & 14.37 & 2.44 & 5.15 & 2.11 & No \\
\hline DQ551953 & 28 & 12.23 & 14.25 & 3.34 & 5.11 & 1.53 & No \\
\hline DQ541776 & 29 & 3.65 & 14.23 & 1.00 & 5.10 & 5.12 & No \\
\hline DQ541806 & 27 & 19.00 & 14.00 & 5.19 & 5.02 & 0.97 & No \\
\hline DQ540253 & 31 & 27.00 & 14.00 & 7.38 & 5.02 & 0.68 & No \\
\hline DQ686298 & 21 & 7.00 & 14.00 & 1.91 & 5.02 & 2.62 & No \\
\hline DQ706110 & 30 & 23.50 & 14.00 & 6.42 & 5.02 & 0.78 & No \\
\hline DQ545604 & 27 & 17.00 & 14.00 & 4.64 & 5.02 & 1.08 & No \\
\hline n202750 & 30 & 12.00 & 14.00 & 3.28 & 5.02 & 1.53 & No \\
\hline DQ696259 & 29 & 6.00 & 14.00 & 1.64 & 5.02 & 3.06 & No \\
\hline DQ723396 & 30 & 6.00 & 13.50 & 1.64 & 4.84 & 2.95 & No \\
\hline DQ555880 & 27 & 24.25 & 13.30 & 6.63 & 4.77 & 0.72 & No \\
\hline DQ716469 & 31 & 5.40 & 13.08 & 1.48 & 4.69 & 3.18 & No \\
\hline DQ722288 & 28 & 2.00 & 13.00 & 0.55 & 4.66 & 8.53 & Yes \\
\hline DQ558886 & 26 & 4.00 & 13.00 & 1.09 & 4.66 & 4.26 & No \\
\hline DQ548138 & 27 & 6.00 & 13.00 & 1.64 & 4.66 & 2.84 & No \\
\hline DQ566603 & 30 & 9.00 & 13.00 & 2.46 & 4.66 & 1.90 & No \\
\hline DQ694433 & 25 & 19.00 & 13.00 & 5.19 & 4.66 & 0.90 & No \\
\hline DQ559729 & 29 & 16.00 & 13.00 & 4.37 & 4.66 & 1.07 & No \\
\hline DQ541629 & 26 & 10.18 & 12.93 & 2.78 & 4.64 & 1.67 & No \\
\hline DQ540202 & 31 & 16.50 & 12.50 & 4.51 & 4.48 & 0.99 & No \\
\hline DQ710188 & 27 & 2.00 & 12.00 & 0.55 & 4.30 & 7.87 & No \\
\hline DQ541627 & 28 & 11.00 & 12.00 & 3.01 & 4.30 & 1.43 & No \\
\hline DQ725115 & 29 & 46.00 & 12.00 & 12.57 & 4.30 & 0.34 & No \\
\hline DQ715208 & 24 & 0.50 & 12.00 & 0.14 & 4.30 & 31.49 & No \\
\hline DQ718174 & 22 & 5.50 & 12.00 & 1.50 & 4.30 & 2.86 & No \\
\hline DQ690565 & 31 & 9.00 & 12.00 & 2.46 & 4.30 & 1.75 & No \\
\hline DQ721627 & 30 & 36.00 & 12.00 & 9.84 & 4.30 & 0.44 & No \\
\hline DQ563182 & 31 & 4.00 & 12.00 & 1.09 & 4.30 & 3.94 & No \\
\hline DQ725966 & 19 & 12.33 & 11.67 & 3.37 & 4.18 & 1.24 & No \\
\hline DQ717747 & 32 & 14.00 & 11.33 & 3.83 & 4.06 & 1.06 & No \\
\hline DQ698641 & 27 & 1.00 & 11.00 & 0.27 & 3.94 & 14.44 & No \\
\hline DQ705481 & 22 & 7.00 & 11.00 & 1.91 & 3.94 & 2.06 & No \\
\hline DQ702236 & 29 & 7.00 & 11.00 & 1.91 & 3.94 & 2.06 & No \\
\hline DQ697536 & 31 & 9.10 & 10.92 & 2.49 & 3.91 & 1.57 & No \\
\hline DQ693633 & 30 & 17.67 & 10.50 & 4.83 & 3.76 & 0.78 & No \\
\hline DQ692951 & 30 & 9.07 & 10.50 & 2.48 & 3.76 & 1.52 & No \\
\hline DQ558403 & 26 & 8.33 & 10.42 & 2.28 & 3.73 & 1.64 & No \\
\hline DQ716691 & 28 & 11.87 & 10.33 & 3.24 & 3.70 & 1.14 & No \\
\hline DQ548430 & 30 & 11.17 & 10.08 & 3.05 & 3.62 & 1.18 & No \\
\hline DQ709071 & 29 & 8.17 & 10.00 & 2.23 & 3.59 & 1.61 & No \\
\hline DQ568824 & 30 & 4.00 & 10.00 & 1.09 & 3.59 & 3.28 & No \\
\hline DQ709273 & 31 & 11.00 & 10.00 & 3.01 & 3.59 & 1.19 & No \\
\hline DQ719680 & 26 & 5.00 & 10.00 & 1.37 & 3.59 & 2.62 & No \\
\hline DQ719784 & 21 & 12.00 & 10.00 & 3.28 & 3.59 & 1.09 & No \\
\hline DQ691624 & 22 & 12.60 & 10.00 & 3.44 & 3.59 & 1.04 & No \\
\hline DQ719096 & 29 & 6.10 & 9.98 & 1.67 & 3.58 & 2.15 & No \\
\hline DQ693813 & 30 & 13.17 & 9.98 & 3.60 & 3.58 & 1.00 & No \\
\hline DQ709946 & 26 & 4.83 & 9.83 & 1.32 & 3.53 & 2.67 & No \\
\hline DQ540134 & 28 & 3.00 & 9.83 & 0.82 & 3.53 & 4.30 & No \\
\hline
\end{tabular}


Supplementary Table 1, continued

\begin{tabular}{|c|c|c|c|c|c|c|c|}
\hline $\begin{array}{l}\text { piRNA } \\
\text { accession }\end{array}$ & Length & $\begin{array}{c}\text { Number of tags in } \\
\text { wildtype cerebellum }\end{array}$ & $\begin{array}{c}\text { Number of tags in } \\
\text { Mecp2 KO cerebellum }\end{array}$ & WT_Tpm & $\begin{array}{c}\text { Mecp2 } \\
\text { KO_Tpm } \\
\end{array}$ & $\begin{array}{c}\text { Fold_change_ } \\
\text { KO/WT }\end{array}$ & $\begin{array}{c}\text { Reported as top } \\
20 \text { piRNAs in brain }\end{array}$ \\
\hline DQ551740 & 30 & 4.80 & 9.75 & 1.31 & 3.50 & 2.67 & No \\
\hline DQ551741 & 32 & 5.00 & 9.75 & 1.37 & 3.50 & 2.56 & No \\
\hline DQ708438 & 31 & 0.50 & 9.50 & 0.14 & 3.41 & 24.93 & No \\
\hline n204129 & 26 & 10.50 & 9.50 & 2.87 & 3.41 & 1.19 & No \\
\hline DQ698521 & 27 & 11.50 & 9.50 & 3.14 & 3.41 & 1.08 & No \\
\hline DQ550765 & 31 & 10.75 & 9.50 & 2.94 & 3.41 & 1.16 & Yes \\
\hline DQ707509 & 31 & 22.50 & 9.25 & 6.15 & 3.32 & 0.54 & No \\
\hline DQ712474 & 28 & 22.50 & 9.25 & 6.15 & 3.32 & 0.54 & No \\
\hline DQ712486 & 30 & 22.50 & 9.25 & 6.15 & 3.32 & 0.54 & No \\
\hline DQ724038 & 21 & 7.23 & 9.17 & 1.98 & 3.29 & 1.66 & No \\
\hline DQ717846 & 29 & 7.83 & 9.08 & 2.14 & 3.26 & 1.52 & No \\
\hline DQ727278 & 29 & 3.00 & 9.00 & 0.82 & 3.23 & 3.94 & No \\
\hline DQ703937 & 31 & 3.17 & 9.00 & 0.87 & 3.23 & 3.73 & No \\
\hline DQ553641 & 29 & 5.00 & 9.00 & 1.37 & 3.23 & 2.36 & No \\
\hline DQ698382 & 31 & 7.00 & 9.00 & 1.91 & 3.23 & 1.69 & No \\
\hline DQ547060 & 30 & 5.83 & 8.92 & 1.59 & 3.20 & 2.01 & No \\
\hline DQ554102 & 30 & 4.83 & 8.57 & 1.32 & 3.07 & 2.33 & No \\
\hline DQ541631 & 30 & 5.75 & 8.50 & 1.57 & 3.05 & 1.94 & No \\
\hline DQ694480 & 28 & 4.42 & 8.33 & 1.21 & 2.99 & 2.48 & No \\
\hline DQ562379 & 25 & 8.83 & 8.17 & 2.41 & 2.93 & 1.21 & No \\
\hline DQ703493 & 26 & 7.05 & 8.13 & 1.93 & 2.92 & 1.51 & No \\
\hline DQ699015 & 30 & 8.00 & 8.00 & 2.19 & 2.87 & 1.31 & No \\
\hline DQ565695 & 31 & 4.00 & 8.00 & 1.09 & 2.87 & 2.62 & No \\
\hline DQ687262 & 30 & 16.00 & 8.00 & 4.37 & 2.87 & 0.66 & No \\
\hline DQ540853 & 26 & 1.00 & 8.00 & 0.27 & 2.87 & 10.50 & No \\
\hline DQ541719 & 29 & 4.00 & 8.00 & 1.09 & 2.87 & 2.62 & No \\
\hline DQ721809 & 29 & 5.00 & 8.00 & 1.37 & 2.87 & 2.10 & No \\
\hline DQ686705 & 26 & 3.00 & 8.00 & 0.82 & 2.87 & 3.50 & No \\
\hline DQ719574 & 27 & 9.50 & 8.00 & 2.60 & 2.87 & 1.11 & No \\
\hline DQ698794 & 29 & 11.00 & 8.00 & 3.01 & 2.87 & 0.95 & No \\
\hline DQ569658 & 30 & 13.67 & 7.67 & 3.73 & 2.75 & 0.74 & No \\
\hline DQ684777 & 30 & 16.33 & 7.67 & 4.46 & 2.75 & 0.62 & No \\
\hline DQ548429 & 28 & 8.67 & 7.58 & 2.37 & 2.72 & 1.15 & No \\
\hline DQ569911 & 31 & 3.83 & 7.50 & 1.05 & 2.69 & 2.57 & No \\
\hline DQ714299 & 28 & 2.25 & 7.50 & 0.61 & 2.69 & 4.37 & No \\
\hline DQ705429 & 28 & 2.02 & 7.48 & 0.55 & 2.68 & 4.87 & No \\
\hline DQ700644 & 30 & 10.00 & 7.33 & 2.73 & 2.63 & 0.96 & No \\
\hline DQ542520 & 32 & 8.40 & 7.27 & 2.30 & 2.61 & 1.14 & No \\
\hline DQ725358 & 22 & 7.88 & 7.22 & 2.15 & 2.59 & 1.20 & No \\
\hline DQ715253 & 28 & 4.57 & 7.08 & 1.25 & 2.54 & 2.04 & No \\
\hline DQ540081 & 28 & 5.00 & 7.00 & 1.37 & 2.51 & 1.84 & No \\
\hline DQ559964 & 27 & 1.00 & 7.00 & 0.27 & 2.51 & 9.19 & No \\
\hline DQ555047 & 31 & 13.00 & 7.00 & 3.55 & 2.51 & 0.71 & No \\
\hline DQ546953 & 32 & 7.00 & 7.00 & 1.91 & 2.51 & 1.31 & No \\
\hline DQ697785 & 18 & 18.00 & 7.00 & 4.92 & 2.51 & 0.51 & No \\
\hline DQ712498 & 27 & 14.00 & 7.00 & 3.83 & 2.51 & 0.66 & No \\
\hline DQ703255 & 29 & 2.00 & 7.00 & 0.55 & 2.51 & 4.59 & No \\
\hline DQ703079 & 27 & 5.00 & 7.00 & 1.37 & 2.51 & 1.84 & No \\
\hline DQ559781 & 28 & 5.00 & 7.00 & 1.37 & 2.51 & 1.84 & No \\
\hline DQ726397 & 22 & 1.00 & 7.00 & 0.27 & 2.51 & 9.19 & No \\
\hline DQ540951 & 28 & 106.00 & 7.00 & 28.96 & 2.51 & 0.09 & No \\
\hline DQ707442 & 32 & 1.17 & 7.00 & 0.32 & 2.51 & 7.87 & No \\
\hline DQ695733 & 31 & 1.17 & 7.00 & 0.32 & 2.51 & 7.87 & No \\
\hline DQ550956 & 30 & 2.00 & 6.67 & 0.55 & 2.39 & 4.37 & No \\
\hline DQ704045 & 30 & 2.00 & 6.67 & 0.55 & 2.39 & 4.37 & No \\
\hline DQ698371 & 26 & 4.50 & 6.50 & 1.23 & 2.33 & 1.90 & No \\
\hline DQ540939 & 26 & 4.50 & 6.50 & 1.23 & 2.33 & 1.90 & No \\
\hline DQ686264 & 26 & 5.33 & 6.33 & 1.46 & 2.27 & 1.56 & No \\
\hline
\end{tabular}


Supplementary Table 1, continued

\begin{tabular}{|c|c|c|c|c|c|c|c|}
\hline $\begin{array}{l}\text { piRNA } \\
\text { accession }\end{array}$ & Length & $\begin{array}{c}\text { Number of tags in } \\
\text { wildtype cerebellum }\end{array}$ & $\begin{array}{c}\text { Number of tags in } \\
\text { Mecp2 KO cerebellum }\end{array}$ & WT_Tpm & $\begin{array}{c}\text { Mecp2 } \\
\text { KO_Tpm }\end{array}$ & $\begin{array}{c}\text { Fold_change_ } \\
\text { KO/WT }\end{array}$ & $\begin{array}{c}\text { Reported as top } \\
20 \text { piRNAs in brain }\end{array}$ \\
\hline DQ550027 & 30 & 1.20 & 6.33 & 0.33 & 2.27 & 6.93 & No \\
\hline DQ543701 & 30 & 10.17 & 6.33 & 2.78 & 2.27 & 0.82 & No \\
\hline DQ554152 & 31 & 3.85 & 6.18 & 1.05 & 2.22 & 2.11 & No \\
\hline DQ550614 & 31 & 7.42 & 6.13 & 2.03 & 2.20 & 1.09 & No \\
\hline DQ557476 & 29 & 5.08 & 6.08 & 1.39 & 2.18 & 1.57 & No \\
\hline DQ723756 & 31 & 0.83 & 6.08 & 0.23 & 2.18 & 9.58 & No \\
\hline DQ694583 & 30 & 2.00 & 6.00 & 0.55 & 2.15 & 3.94 & No \\
\hline DQ541882 & 32 & 2.25 & 6.00 & 0.61 & 2.15 & 3.50 & No \\
\hline DQ563242 & 30 & 1.00 & 6.00 & 0.27 & 2.15 & 7.87 & No \\
\hline DQ714655 & 21 & 2.50 & 6.00 & 0.68 & 2.15 & 3.15 & No \\
\hline DQ708131 & 27 & 3.00 & 6.00 & 0.82 & 2.15 & 2.62 & Yes \\
\hline DQ565679 & 30 & 2.50 & 6.00 & 0.68 & 2.15 & 3.15 & No \\
\hline DQ695473 & 27 & 3.50 & 6.00 & 0.96 & 2.15 & 2.25 & No \\
\hline DQ551797 & 29 & 5.00 & 6.00 & 1.37 & 2.15 & 1.57 & No \\
\hline n202533 & 30 & 3.00 & 6.00 & 0.82 & 2.15 & 2.62 & No \\
\hline DQ719363 & 29 & 3.50 & 6.00 & 0.96 & 2.15 & 2.25 & No \\
\hline DQ564810 & 31 & 3.00 & 6.00 & 0.82 & 2.15 & 2.62 & No \\
\hline DQ542432 & 29 & 3.50 & 6.00 & 0.96 & 2.15 & 2.25 & No \\
\hline DQ687025 & 30 & 2.00 & 6.00 & 0.55 & 2.15 & 3.94 & No \\
\hline DQ705141 & 29 & 3.00 & 6.00 & 0.82 & 2.15 & 2.62 & No \\
\hline DQ550009 & 32 & 2.50 & 6.00 & 0.68 & 2.15 & 3.15 & No \\
\hline DQ712132 & 27 & 3.92 & 5.92 & 1.07 & 2.12 & 1.98 & No \\
\hline DQ710634 & 26 & 3.92 & 5.92 & 1.07 & 2.12 & 1.98 & No \\
\hline DQ688047 & 31 & 0.90 & 5.87 & 0.25 & 2.10 & 8.55 & No \\
\hline DQ540133 & 27 & 3.00 & 5.83 & 0.82 & 2.09 & 2.55 & No \\
\hline DQ724045 & 31 & 5.17 & 5.83 & 1.41 & 2.09 & 1.48 & No \\
\hline DQ717785 & 29 & 3.67 & 5.67 & 1.00 & 2.03 & 2.03 & No \\
\hline DQ697835 & 30 & 0.90 & 5.62 & 0.25 & 2.01 & 8.19 & No \\
\hline DQ550424 & 30 & 6.95 & 5.62 & 1.90 & 2.01 & 1.06 & No \\
\hline DQ699107 & 32 & 5.08 & 5.55 & 1.39 & 1.99 & 1.43 & No \\
\hline DQ692222 & 31 & 4.08 & 5.55 & 1.12 & 1.99 & 1.78 & No \\
\hline DQ559632 & 29 & 5.03 & 5.52 & 1.38 & 1.98 & 1.44 & No \\
\hline DQ539909 & 31 & 3.50 & 5.50 & 0.96 & 1.97 & 2.06 & No \\
\hline DQ699690 & 29 & 3.00 & 5.50 & 0.82 & 1.97 & 2.41 & No \\
\hline DQ694268 & 30 & 6.17 & 5.50 & 1.68 & 1.97 & 1.17 & No \\
\hline DQ704413 & 30 & 3.50 & 5.50 & 0.96 & 1.97 & 2.06 & No \\
\hline DQ540217 & 30 & 2.50 & 5.50 & 0.68 & 1.97 & 2.89 & No \\
\hline DQ705397 & 27 & 3.00 & 5.50 & 0.82 & 1.97 & 2.41 & No \\
\hline DQ541518 & 32 & 2.83 & 5.42 & 0.77 & 1.94 & 2.51 & No \\
\hline DQ561657 & 31 & 2.87 & 5.30 & 0.78 & 1.90 & 2.43 & No \\
\hline DQ713688 & 20 & 6.47 & 5.27 & 1.77 & 1.89 & 1.07 & No \\
\hline DQ695662 & 27 & 0.20 & 5.25 & 0.05 & 1.88 & 34.45 & No \\
\hline DQ554873 & 32 & 1.92 & 5.03 & 0.52 & 1.80 & 3.45 & No \\
\hline DQ718455 & 31 & 1.92 & 5.03 & 0.52 & 1.80 & 3.45 & No \\
\hline DQ569362 & 29 & 2.00 & 5.00 & 0.55 & 1.79 & 3.28 & No \\
\hline DQ711635 & 30 & 2.00 & 5.00 & 0.55 & 1.79 & 3.28 & No \\
\hline DQ541249 & 31 & 5.00 & 5.00 & 1.37 & 1.79 & 1.31 & No \\
\hline DQ718385 & 28 & 6.00 & 5.00 & 1.64 & 1.79 & 1.09 & No \\
\hline DQ701776 & 29 & 38.00 & 5.00 & 10.38 & 1.79 & 0.17 & No \\
\hline DQ561111 & 29 & 2.00 & 5.00 & 0.55 & 1.79 & 3.28 & No \\
\hline DQ697860 & 31 & 8.00 & 5.00 & 2.19 & 1.79 & 0.82 & No \\
\hline DQ541101 & 27 & 5.50 & 5.00 & 1.50 & 1.79 & 1.19 & No \\
\hline DQ691503 & 28 & 0.00 & 5.00 & 0.00 & 1.79 & 5.00 & No \\
\hline DQ701204 & 27 & 6.00 & 5.00 & 1.64 & 1.79 & 1.09 & No \\
\hline DQ695609 & 26 & 8.50 & 5.00 & 2.32 & 1.79 & 0.77 & No \\
\hline DQ545504 & 27 & 10.00 & 5.00 & 2.73 & 1.79 & 0.66 & No \\
\hline DQ696494 & 26 & 0.00 & 5.00 & 0.00 & 1.79 & 5.00 & No \\
\hline DQ726803 & 30 & 1.00 & 5.00 & 0.27 & 1.79 & 6.56 & No \\
\hline
\end{tabular}


Supplementary Table 1, continued

\begin{tabular}{lcccccc}
\hline $\begin{array}{l}\text { piRNA } \\
\text { accession }\end{array}$ & Length & $\begin{array}{c}\text { Number of tags in } \\
\text { wildtype cerebellum }\end{array}$ & $\begin{array}{c}\text { Number of tags in } \\
\text { Mecp2 KO cerebellum }\end{array}$ & WT_Tpm & $\begin{array}{c}\text { Mecp2 } \\
\text { KO_Tpm }\end{array}$ & $\begin{array}{c}\text { Fold_change_ } \\
\text { KO/WT }\end{array}$ \\
\hline DQ695702 & 32 & 0.00 & 5.00 & 0.00 & 1.79 & 5.00 \\
20 piRNAs in brain
\end{tabular}




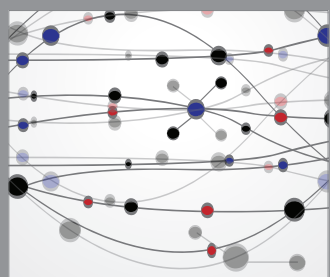

The Scientific World Journal
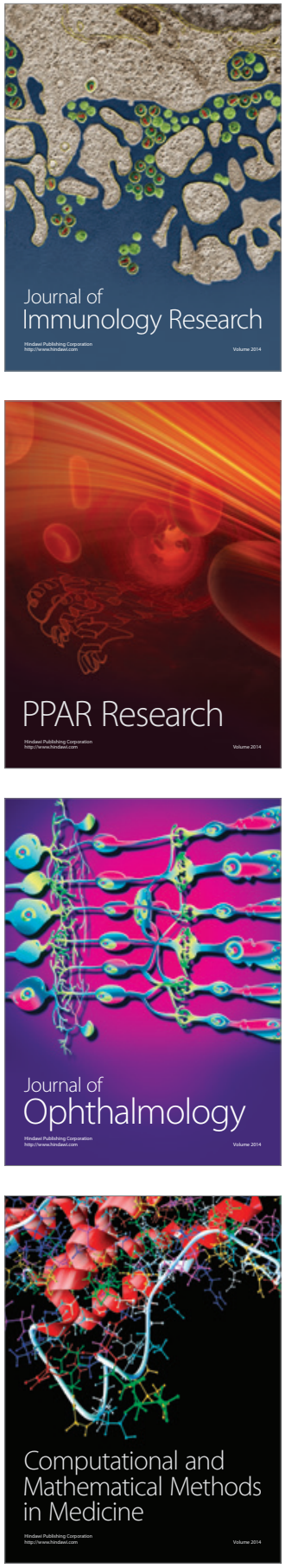

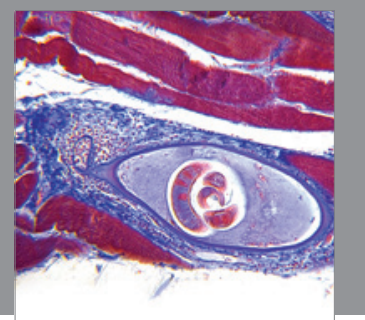

Gastroenterology

Research and Practice
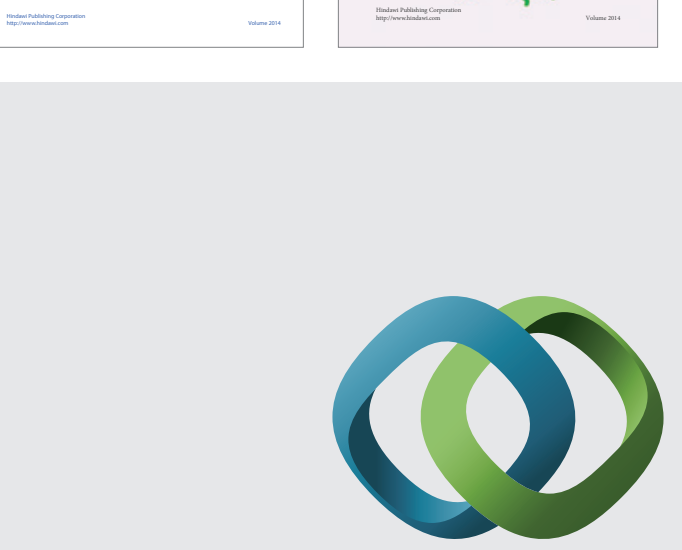

\section{Hindawi}

Submit your manuscripts at

http://www.hindawi.com
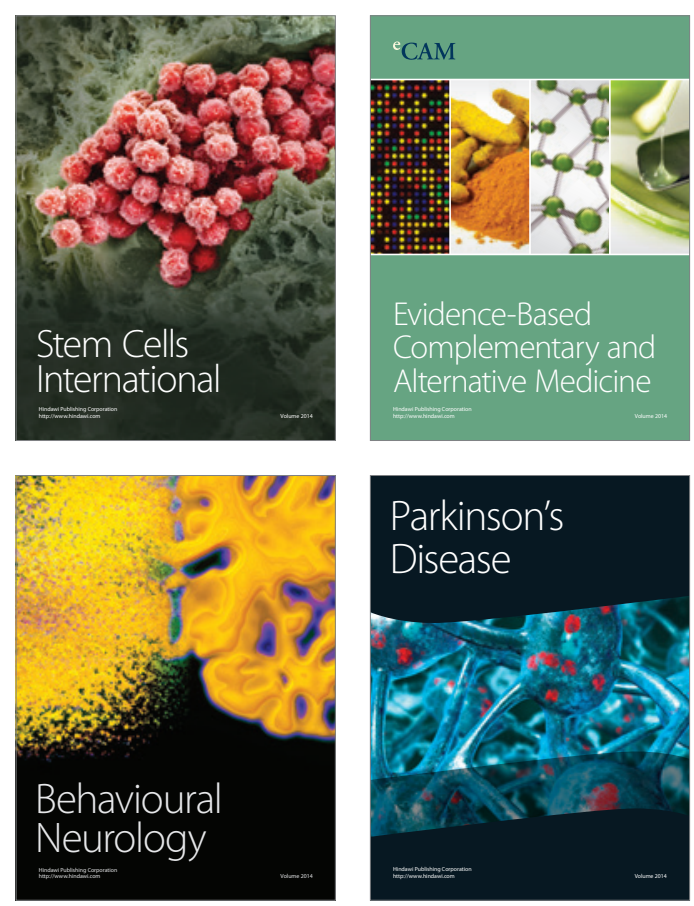

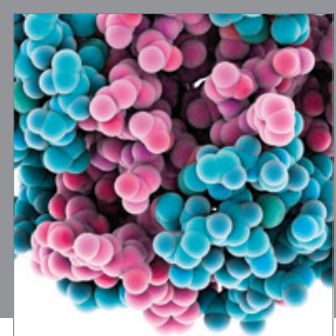

Journal of
Diabetes Research

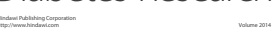

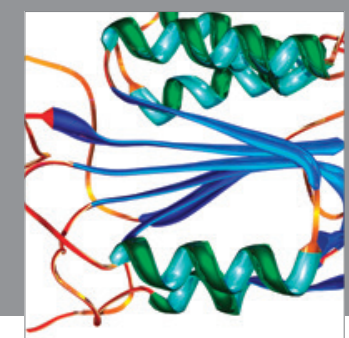

Disease Markers
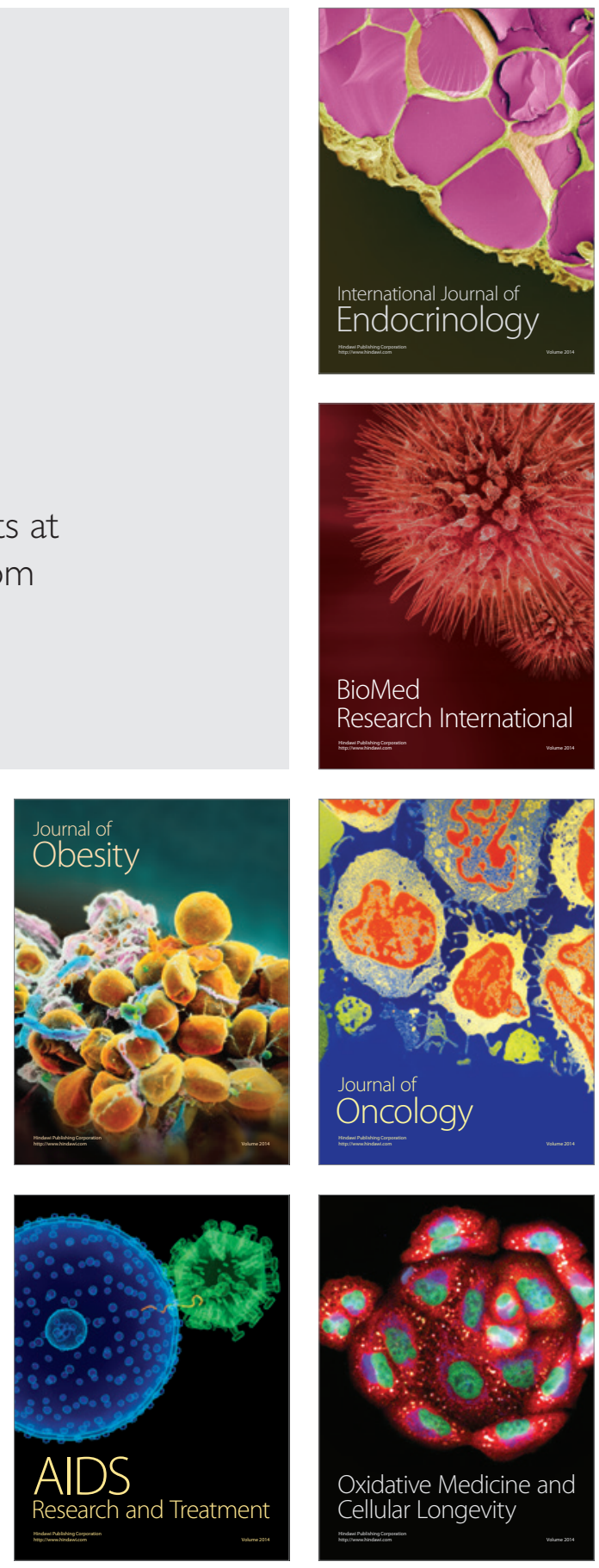